\title{
Prospective study of giant paraesophageal hernia repair with 1-year follow-up
}

\author{
John R. Stringham, MD, ${ }^{a}$ Jennifer V. Phillips, RN, ${ }^{a}$ Timothy L. McMurry, PhD, ${ }^{b}$ Drew L. Lambert, MD,
} David R. Jones, MD, ${ }^{\mathrm{d}}$ James M. Isbell, MD, ${ }^{\mathrm{d}}$ Christine L. Lau, MD, ${ }^{\mathrm{a}}$ and Benjamin D. Kozower, MD, MPH

\section{ABSTRACT}

Objective: Evaluating giant paraesophageal hernia (GPEH) repair requires longterm follow-up. GPEH repair can have associated high recurrence rates, yet this incidence depends on how recurrence is defined. Our objective was to prospectively evaluate patients undergoing GPEH repair with 1-year follow-up.

Methods: Patients undergoing elective GPEH repair between 2011 and 2014 were enrolled prospectively. Postoperatively, patients were evaluated at 1 month and 1 year. Radiographic recurrence was evaluated by barium swallow and defined as a gastroesophageal junction located above the hiatus. Quality of life was evaluated pre- and postoperatively with the use of a validated questionnaire.

Results: One-hundred six patients were enrolled. The majority of GPEH repairs were performed laparoscopically $(80.2 \%)$, and $7.5 \%$ were redo repairs. At 1-year follow-up, $63.4 \%$ of patients were symptom free, and radiographic recurrence was $32.7 \%$. Recurrence rate was $18.8 \%$ with standard definition ( $>2 \mathrm{~cm}$ of stomach above the diaphragm). Quality of life scores at 1 year were significantly better after operative repair, even in patients with radiographic recurrence (7.0 vs 22.5 all patients, 13.0 vs 22.5 with recurrence; $P<.001$ ). Patients with small radiographic recurrences have similar satisfaction and symptom severity to patients with $>2 \mathrm{~cm}$ recurrences.

Conclusions: GPEH repair can be performed with low operative mortality and morbidity. The rate of recurrence at 1 year depends on the definition used. Patient satisfaction and symptom severity are similar between patients with radiographic and greater than $2 \mathrm{~cm}$ hernia recurrences. Longer follow-up and critical assessment of our results are needed to understand the true impact of this procedure and better inform perioperative decision making. (J Thorac Cardiovasc Surg 2017;154:743-51)

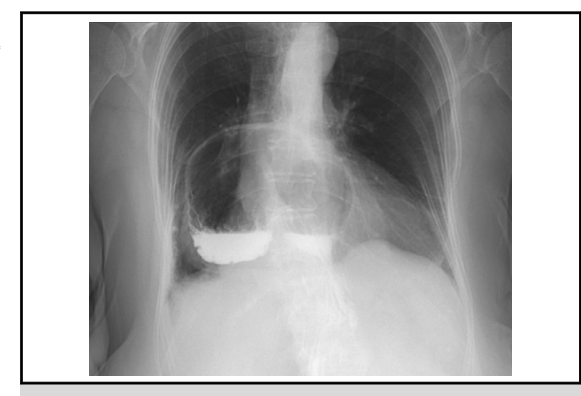

Barium swallow study of a giant paraesophageal hernia.

\section{Central Message}

Small paraesophageal hernia recurrences at 1year follow-up have similar satisfaction and symptom scores as those with larger recurrences.

\section{Perspective}

Giant paraesophageal hernias pose a significant challenge to the surgeon, with high recurrence rates. Patients with small recurrences at 1-year follow-up have similar satisfaction and symptom scores as those with $>2 \mathrm{~cm}$ recurrences. These smaller recurrences are not widely reported in the literature, and may be under-studied.

See Editorial Commentary page 752.
Paraesophageal hernias (PEHs) are an uncommon finding that can adversely affect patient well-being. Approximately

\footnotetext{
From the Divisions of ${ }^{\mathrm{a}}$ Thoracic and Cardiovascular Surgery and ${ }^{\mathrm{b}}$ Public Health Sciences, and ${ }^{\mathrm{c}}$ Department of Radiology, University of Virginia Health Sciences Center, Charlottesville, Va; ${ }^{\mathrm{d} D i v i s i o n}$ of Thoracic Surgery, Memorial Sloan Kettering Cancer Center, New York, NY; and ${ }^{\mathrm{e}}$ Division of Cardiothoracic Surgery, Washington University School of Medicine, St Louis, Mo.

Read at the 96th Annual Meeting of The American Association for Thoracic Surgery, Baltimore, Maryland, May 14-18, 2016.

Received for publication June 8, 2016; revisions received Feb 13, 2017; accepted for publication March 6, 2017; available ahead of print May 11, 2017.

Address for reprints: Benjamin D. Kozower, MD, MPH, Division of Cardiothoracic Surgery, Washington University School of Medicine, 660 S Euclid Ave, Campus Box 8234, St Louis, MO 63110 (E-mail: kozowerb@wudosis.wustl.edu). $0022-5223 / \$ 36.00$

Copyright (C) 2017 by The American Association for Thoracic Surgery http://dx.doi.org/10.1016/j.jtcvs.2017.03.138
}

$5 \%$ of all hiatal hernias are considered to be a PEH, defined as the herniation of the fundus of the stomach through the esophageal hiatus in the diaphragm into a true hernia sac. Giant paraesophageal hernias (GPEHs) are PEHs with greater than $30 \%$ of the stomach above the diaphragm. A GPEH constitutes a clinical challenge that requires advanced operative techniques to ensure consistent and lasting results. Over time, the safety and reliability of GPEH repair has improved, with laparoscopic results frequently

Scanning this $\mathrm{QR}$ code will take you to the article title page. To view the AATS 2016 Webcast, see the URL next to the video thumbnail. 


\section{Abbreviations and Acronyms \\ GERD-HRQL $=$ Gastroesophageal Reflux \\ Disease-Health-Related Quality \\ of Life

$\begin{array}{ll}\text { GPEH } & =\text { giant paraesophageal hernia } \\ \text { IQR } & =\text { interquartile range } \\ \text { PEH } & =\text { paraesophageal hernia }\end{array}$

reported in the literature. ${ }^{1-3}$ However, even with the best operative technique, hernia recurrence rates remain high, ranging from $15 \%$ to $66 \%$ in reported studies. ${ }^{1-4}$ In addition, questions remain regarding the most appropriate operative techniques to minimize hernia recurrence and to identify which patient population will benefit the most from techniques such as gastroplasty or mesh crural reinforcement. ${ }^{5-7}$

Several prominent institutions have performed retrospective reviews of their experience treating GPEH. ${ }^{3,8-11}$ However, few studies have examined the results of GPEH repair in a prospective manner with routine imaging postoperatively. The prospective data with routine postoperative barium swallow studies that do exist are hindered by small study populations or low patient participation at long-term follow-up. ${ }^{12,13}$ Therefore, the objective of this trial was to evaluate prospectively all patients undergoing elective repair of GPEH and to evaluate these patients for recurrence and measures of quality of life. We also wanted to determine the frequency of small radiographic recurrences, less than $2 \mathrm{~cm}$ in size, which frequently are not reported in the literature.

\section{MATERIALS AND METHODS \\ Patient Selection}

This prospective cohort study was approved by the University of Virginia Institutional Review Board (IRB \#15872). All patients undergoing elective GPEH repair via any approach (laparoscopic, open laparotomy, or open thoracotomy) during the time period of November 2011 to December 2014 were identified preoperatively. These individuals were enrolled prospectively in this study; exclusion criteria included any subject who underwent esophageal surgery for a malignant disease process, any subject unwilling to provide informed consent, or any individual who was unwilling to undergo the required follow-up barium swallow studies and questionnaires. For this analysis, only those patients identified with a GPEH were included in the analysis. GPEH was defined as gastric herniation of $30 \%$ or more through the diaphragmatic hiatus on preoperative imaging. ${ }^{14}$

\section{Patient Demographics and GPEH Characterization}

Preoperative characteristics, medical comorbidities, and clinical information regarding GPEH characteristics were all recorded prospectively by trained research personnel and recorded into a secure surgical outcomes database.

\section{Surgical Technique}

All operations were performed by 4 surgeons at a single institution. Our preferred operative approach was laparoscopic. Left thoracotomy (Belsey
Mark $\mathrm{IV}^{11}$ ) or laparotomy was used for a majority of the redo hernia repairs or for patients with significant other intra-abdominal surgery. Regardless of operative approach, we emphasized meticulous preservation of crural integrity, complete hernia sac excision, and routine gastroesophageal fatpad dissection. If there was not $3 \mathrm{~cm}$ of tension free, intra-abdominal esophagus, we performed a Collis gastroplasty (via left thoracotomy) or a totally intra-abdominal Collis wedge gastroplasty (laparoscopy or laparotomy) to augment esophageal length. ${ }^{15}$ Use of a Nissen or partial fundoplication was based on esophageal motility results and surgeon discretion. In our laparoscopic patients, we placed gastropexy sutures from the posterior left and right portions of the fundoplication to the right and left crus, respectively. No patient received mesh buttressing of the crura in this series.

Postoperatively, patients typically were started on a clear liquid diet and advanced quickly to a full liquid diet for 2 weeks postoperatively; a registered dietitian assisted with teaching in all patients before discharge.

\section{Evaluation of Quality of Life and Satisfaction}

All patients received the previously validated Gastroesophageal Reflux Disease-Health-Related Quality of Life (GERD-HRQL) questionnaire preoperatively and at postoperative time points of 1 month and 1 year. ${ }^{16}$ The questionnaire consists of 10 questions with a maximum score of 50 (6 questions related to gastroesophageal reflux disease, 2 questions related to swallowing, 1 question related to bloating, and 1 for medication use). A greater score indicates a worse symptom severity. Patient satisfaction with their current condition was determined at each time point. These questionnaires were administered by trained personnel during scheduled clinic visits.

Patients routinely had a barium swallow postoperatively before discharge but did not undergo a barium swallow study at the 1-month time point unless indicated by symptoms. At 1 year, all patients received a barium swallow study to ascertain the presence of a recurrence, regardless of symptoms. We defined recurrence in 2 ways to evaluate our results critically and be consistent with the majority of published series. Because the majority of prominent literature published on the repair of GPEH defines a recurrence as over $2 \mathrm{~cm}$ or $10 \%$ of the stomach above the diaphragm, this is defined as a "conventionally defined recurrence."3,12,17 A "radiographic recurrence" is defined as any stomach present above the diaphragm that is less than $2 \mathrm{~cm}$ in size. To ensure consistency and objectivity, this was determined by a single radiologist blinded to the rest of the clinical data (D.L.).

\section{Statistical Analyses}

Data were described with counts and percentages for categorical data, and medians with interquartile ranges (IQRs) for continuous data. Changes in continuous variables for the entire cohort were compared with the Wilcoxon signed rank test, whereas differences in symptoms, stratified by hernia recurrence, were compared with the Kruskal-Wallis test with change from baseline to 12 months as the outcome. All statistical analyses were performed using the statistical software R, version 3.2.4 (R Foundation for Statistical Computing, Vienna, Austria).

\section{RESULTS \\ Patient Demographics and GPEH Characterization}

Patient demographics and GPEH characterization are shown in Table 1. We enrolled 106 patients. Only one patient declined inclusion into the study, and one prisoner was excluded. Median age of participants was 68 years. Preoperative mean body mass index was 29.4; 45 patients $(42.5 \%)$ were characterized as obese (body mass index $\geq 30)$. The majority of patients $(69 \%)$ had major 
TABLE 1. Demographics and preoperative presentation

\begin{tabular}{|c|c|c|}
\hline & $\mathbf{N}=106$ & $\%$ \\
\hline \multicolumn{3}{|l|}{ Demographics } \\
\hline Female sex & 79 & 74.5 \\
\hline Median age, y, IQR & 68 & $59-74$ \\
\hline \multicolumn{3}{|l|}{ BMI } \\
\hline \multicolumn{3}{|l|}{ Preoperative BMI } \\
\hline Underweight (BMI < 18.5) & 0 & 0 \\
\hline Ideal weight (BMI 18.5 up to 25 ) & 20 & 18.9 \\
\hline Overweight (BMI 25 up to 30) & 41 & 38.7 \\
\hline Obese (BMI 30 up to 35 ) & 30 & 28.3 \\
\hline Super obese $(\mathrm{BMI}>35)$ & 15 & 14.2 \\
\hline Mean BMI $( \pm$ SD $)$ & $29.4 \pm 4.8$ & \\
\hline \multicolumn{3}{|l|}{ Comorbidities } \\
\hline Major comorbid disease present & 69 & 65.1 \\
\hline \multicolumn{3}{|l|}{ Comorbidity type } \\
\hline Hypertension & 52 & \\
\hline Respiratory disease & 16 & \\
\hline Coronary artery disease & 13 & \\
\hline Cerebrovascular accident & 6 & \\
\hline Renal insufficiency & 6 & \\
\hline Congestive heart failure & 3 & \\
\hline Peripheral vascular disease & 1 & \\
\hline Previous abdominal operation & 52 & 49.1 \\
\hline Redo paraesophageal hernia repair & 8 & 7.5 \\
\hline \multicolumn{3}{|l|}{ Hernia characteristics } \\
\hline \multicolumn{3}{|l|}{ Paraesophageal hernia type } \\
\hline Type II & 6 & 5.7 \\
\hline Type III & 86 & 81.1 \\
\hline Type IV & 14 & 13.2 \\
\hline \multicolumn{3}{|l|}{ Percent of stomach herniated } \\
\hline $30-49$ & 20 & 19.2 \\
\hline $50-74$ & 38 & 36.5 \\
\hline $75-99$ & 21 & 20.2 \\
\hline 100 & 18 & 17.3 \\
\hline Mean $\%$ stomach in chest $( \pm \mathrm{SD})$ & $61 \pm 25.1$ & \\
\hline
\end{tabular}

$I Q R$, Interquartile range; $B M I$, body mass index; $S D$, standard deviation.

medical comorbidities. Fifty-two patients $(49.1 \%)$ had undergone a previous abdominal operation, and 8 patients $(7.5 \%)$ underwent a reoperative GPEH repair.

Preoperative workup for most patients included barium swallow (78 patients); 54 received computed tomography scans (usually referred with the study already performed), and 26 patients received multiple imaging studies. Type III hernias predominated $(\mathrm{n}=86,81.1 \%)$, with 14 patients $(13.2 \%)$ found to have a type IV hernia; colon was the most common organ found in these hernias. The GPEH were large, with an average of $60 \%$ of the stomach herniated through the diaphragmatic hiatus into the mediastinum. Fifty-nine patients $(37.5 \%)$ had more than $75 \%$ of their stomach in their chest.

\section{Operative Approach}

The majority of patients $(\mathrm{n}=85$, or $80.2 \%)$ had their operation completed laparoscopically, whereas only 1 patient $(0.9 \%)$ required conversion to an open procedure.
TABLE 2. Postoperative results

\begin{tabular}{lcc}
\hline & $\mathbf{N}=\mathbf{1 0 6}$ & $\%$ \\
\hline Mortality & & \\
In-hospital 30-d mortality & 0 & 0 \\
Mortality after 1 mo & 1 & 0.9 \\
Mortality after 1 y & 5 & 4.7 \\
Complications & & 73.6 \\
No complications & 78 & 23.5 \\
Minor & 25 & \\
Arrhythmia & 11 & \\
Transient hypoxia & 3 & \\
Delirium & 2 & \\
UTI & 2 & \\
Dysphagia & 2 & \\
Pleural effusion & 2 & \\
Pneumothorax & 1 & \\
DVT & 1 & \\
Gastroparesis & 1 & \\
Major & 6.6 & \\
Reoperation & 4 & \\
Stroke & 1 & \\
Postoperative leak & 1 & \\
\hline$U T I$, Urinary tract infection; $D V T$, deep vein thrombosis. &
\end{tabular}

UTI, Urinary tract infection; $D V T$, deep vein thrombosis.

Two patients $(1.9 \%)$ had a planned laparotomy. Eighteen patients $(17.0 \%)$ were repaired via a thoracic approach with a Belsey Mark IV procedure. The majority of patients who received a thoracotomy had previous upper gastrointestinal surgery. We performed a partial fundoplication in $80.2 \%$ of patients $(\mathrm{n}=85)$, and an esophageal lengthening procedure was performed in $66 \%(\mathrm{n}=70)$ of patients.

\section{Perioperative Morbidity and Mortality}

Postoperative morbidity and mortality results are shown in Table 2. In-hospital or 30-day mortality was zero. One patient died on day 55, after discharge on day 35 , and before his follow-up appointment. Four other patients died within 1 year of operation; 2 from myocardial infarction, 1 from aspiration pneumonia, and 1 from metastatic ovarian cancer (known at the time of surgery but who was treated because of severe symptomatic gastric volvulus).

The majority of patients, $73.6 \%(\mathrm{n}=78)$, had no immediate postoperative complications. Minor in-hospital complications occurred in $20.8 \%(\mathrm{n}=22)$; atrial fibrillation accounted for one half of these. Major complications were rare as well: 4 patients required reoperation ( 2 for immediate recurrence of the hernia, 1 for feeding tube placement for malnourishment and gastroparesis, and 1 for a retained wedge fundectomy). One patient had a small staple line leak that was managed nonoperatively with an interventional drain, and one patient suffered a stroke.

\section{Postoperative Follow-up}

Patients were seen at 1 month and at 1 year after their surgery. The median time to 1-year follow-up was 397 days 
TABLE 3. Postoperative follow-up

\begin{tabular}{|c|c|c|c|c|}
\hline & \multicolumn{2}{|c|}{$1 \mathrm{mo}$} & \multicolumn{2}{|c|}{$12 \mathrm{mo}$} \\
\hline & $\mathbf{N}=\mathbf{1 0 5}$ & $\%$ & $\mathbf{N}=\mathbf{1 0 1}$ & $\%$ \\
\hline Symptom recurrence & 5 & 4.8 & 37 & 36.6 \\
\hline Radiographic hernia recurrence & & & & \\
\hline $\begin{array}{l}\text { (GE junction above diaphragm on } \\
\text { barium study) }\end{array}$ & 2 & 1.9 & 33 & 32.7 \\
\hline $\begin{array}{l}\text { Conventionally defined hernia } \\
\text { recurrence }\end{array}$ & & & & \\
\hline $\begin{array}{l}(>2 \mathrm{~cm} \text { of stomach above } \\
\quad \text { diaphragm on barium study) }\end{array}$ & 0 & 0 & 19 & 18.8 \\
\hline Reintervention required & 4 & 3.8 & 12 & 11.9 \\
\hline
\end{tabular}

GE, Gastroesophageal.

(IQR 380-437). At 1 month, patients were evaluated for symptoms, and if indicated, an additional barium swallow was performed to evaluate for recurrence (Table 3). The 1-month follow-up was conducted on the 105 (of 106) surviving participants. Of these, only 5 patients stated their symptoms had recurred $(4.8 \%)$. Two had received a barium swallow that indicated a recurrence; both of these were small recurrences with less than $2 \mathrm{~cm}$ of stomach found above the diaphragm. Four patients $(3.8 \%)$ required endoscopic reintervention (3 esophageal dilations, 1 stent placement) at 1 month.

Barium swallow results at 1-year follow-up are shown in Table 3. The 1-year follow-up was conducted on the 101 (of $106)$ surviving patients. Thirty-seven patients $(36.6 \%)$ reported symptom recurrence at their follow-up. The radiographic recurrence rate was $32.7 \%$ (33 patients), defined as the gastroesophageal junction or any other portion of the stomach above the diaphragm. We then looked for recurrences as they have been defined traditionally in the pertinent literature, or greater than $2 \mathrm{~cm}$ or $10 \%$ of the stomach above the diaphragm ("conventionally defined recurrences"). With this definition, recurrence rate was $18.8 \%$ (19 patients). At 1 year, 12 patients required reintervention. Most reinterventions were due to stricture: 5 required esophageal dilation, and 1 was treated with endoscopic stent placement at an outside hospital. One patient was treated with botulinum toxin injection of the pylorus for poor gastric emptying. Three patients with symptomatic recurrence underwent reoperation.

\section{Patient Satisfaction and Quality of Life Measures}

To gauge how patient's symptoms changed over time, all patients received the previously validated GERD-HRQL questionnaire. Postoperative satisfaction results are shown in Table 4. Every patient was asked about their satisfaction with their condition at all time points. Preoperatively, only 3 of 105 patients $(2.9 \%)$ stated that they were satisfied with their health condition. At 1-month follow-up, this number significantly increased to 87 patients $(85.3 \%)(P<.001$ vs preoperative satisfaction). At 1 year, satisfaction decreased to $71.4 \%,(P<.001)$. For those patients without a hernia recurrence at 1 year, their rate of satisfaction was similar to that reported 1 month after surgery $(80 \%$, $P<.001)$. When only those patients with a recurrence were examined, satisfaction did not stay at such a high level but was still greater than preoperative satisfaction levels. At 1 month, only 2 patients had a recurrence, and both of these were small $(<2 \mathrm{~cm})$ radiographic recurrences. No comparison could be made with this small cohort. At 12-month follow-up, 14 small radiographic recurrences were found on barium swallow. Importantly, 8 of these 14 patients $(57.1 \%)$ were still satisfied with their condition, but this is lower than patients without a small radiographic recurrence $(P<.001)$. When large hernia recurrences of greater than $2 \mathrm{~cm}$ of stomach over the diaphragm were examined, there was no statistical difference between these and small hernia recurrences. Ten of these 19 patients were still satisfied with their current health status $(52.6 \%)$. This remained significantly greater than their preoperative condition $(P<.001)$.

Finally, the GERD-HRQL questionnaire was administered preoperatively and at the 1-month and 1-year follow-up visits (Table 5). The median total symptom score in all patients preoperatively was 22.5 (IQR 9.3-31.0). One month after the operation, the total score had significantly decreased to 3.0 (IQR 1.0-8.0; $P<.001$ ). After 1 year, this score increased to a median of 7.0 (IQR 2.0-16.5) but was still significantly below preoperative levels $(P<.001)$. When those patients who did not have a recurrence were examined at 1 year, the GERD-HRQL symptom severity score was no different than the 1-month severity score with a median value of 3.5 (IQR 2.0-11.0) and was significantly different from the preoperative symptom score $(P<.001)$. When the median score of those patients who

TABLE 4. Patient satisfaction

\begin{tabular}{|c|c|c|c|c|c|c|}
\hline \multirow[b]{2}{*}{ Satisfaction } & \multicolumn{2}{|c|}{ Preoperative } & \multicolumn{2}{|c|}{$1 \mathrm{mo}$} & \multicolumn{2}{|c|}{12 mo } \\
\hline & $\mathbf{n}$ & $\%$ & $\mathbf{n}$ & $\%$ & $\mathbf{n}$ & $\%$ \\
\hline All patients & $3 / 106$ & 2.8 & $87 / 102$ & $85.3^{*}$ & $70 / 98$ & $71.4^{*}$ \\
\hline No hernia recurrence & & & $85 / 100$ & $85.0^{*}$ & $52 / 65$ & $80.0^{*}$ \\
\hline With small radiologic recurrence $(\leq 2 \mathrm{~cm})$ & & & $2 / 2$ & 100 & $8 / 14$ & $57.1^{*}$ \\
\hline With conventional definition of recurrence $(>2 \mathrm{~cm})$ & & & $0 / 0$ & 0 & $10 / 19$ & $52.6^{*}$ \\
\hline
\end{tabular}

$* P<.001$ versus preoperative satisfaction. 
TABLE 5. Symptom severity score (GERD-HRQL questionnaire)

\begin{tabular}{lcl}
\hline & Median & \multicolumn{1}{c}{ IQR } \\
\hline Preoperative GERD-HRQL score & 22.5 & $(9.3-31.0)$ \\
1-mo GERD-HRQL score (all patients) & $3.0^{*}$ & $(1.0-8.0)$ \\
1-y GERD-HRQL score & $7.0^{*}$ & $(2.0-16.5)$ \\
Without recurrence & $3.5^{*}$ & $(2.0-11.0)$ \\
With any recurrence & 13.0 & $(8.0-27.0)$ \\
$\quad$ Small $(\leq 2 \mathrm{~cm})$ recurrence & 12.0 & $(8.5-28.0)$ \\
Large $(>2 \mathrm{~cm})$ recurrence & 14.0 & $(8.5-25.5)$ \\
\hline
\end{tabular}

IQR, Interquartile range; GERD-HRQL, Gastroesophageal Reflux Disease-HealthRelated Quality of Life. $* P<.001$ versus preoperative satisfaction.

suffered any recurrence was examined, this was lower than the preoperative levels (13.0, IQR 8.0-27.0) but much higher than those patients with no recurrence. To try and understand the significance of small radiographic recurrences, we then examined whether there was a difference in the GERD-HRQL score between the smaller radiographic recurrences less than $2 \mathrm{~cm}$ and the larger recurrences that have been reported in the literature. Our data show that the GERD-HRQL scores were similar in the small $(\leq 2 \mathrm{~cm})$ recurrences (median 12, IQR 8.5-28.0), and the larger $(>2 \mathrm{~cm})$ recurrences (median 14, IQR 8.5-25.5); both types of recurrences had higher symptom scores compared with those with no recurrence at 12 months (median 3.5, IQR 2.0-11.0).

The GERD-HRQL score also can be used to examine what symptoms of GPEH were experienced at each time point. The preoperative and 1 year postoperative results are shown in Table 6. Although the median scores for reflux, swallowing, and bloating appear clinically improved at 1 year for the group of patients without recurrence, these improvements were not statistically significant.

\section{DISCUSSION}

Several excellent studies have been written describing the long-term outcomes of GPEH repair. ${ }^{3,8,9,11}$ The current study attempted to examine the impact of radiologic recurrences and the impact of recurrence on symptoms 1 year after surgery. Aggressive follow-up of these patients was performed to ensure accurate data collection of patient satisfaction and symptom recurrence and severity. This trial showed that the patient population seen at our institution is complex. Most patients were in their seventh or eighth decade, were obese, and had major comorbidities that complicated their perioperative care. The majority of patients also had previous abdominal operations, and $7.5 \%$ had a previous PEH repair. The hernias repaired in this series also were large, with an average of $61 \%$ of the stomach located above the diaphragm. Despite the complexity of these patients, the majority of GPEH repairs were performed laparoscopically $(80 \%)$. Overall, these operations were done safely with an in-hospital mortality rate of zero and a major complication rate of $8.5 \%$.

Because of the prospective nature of this study, we were able to examine almost all patients (101 patients of 105) at 1 year with a barium swallow. When we used a strict definition of recurrence (gastroesophageal junction above the diaphragmatic hiatus), the recurrence rate was $32.7 \%$ at 1 year. This is similar to previously reported radiographic recurrence rates such as Hashemi and colleagues, ${ }^{18}$ with laparoscopic GPEH recurrence rate of $42 \%$. However, most of the prominent publications that have examined recurrence rates after GPEH repair have defined a recurrence as greater than $2 \mathrm{~cm}$ or $10 \%$ of stomach above the hiatus. ${ }^{3,5,12,17}$ When this definition was used in our study, the recurrence rate decreased to $18.8 \%$ at 1 year. This is similar with previously published recurrence rates using this common definition. Lidor and colleagues ${ }^{13}$ in their series of type III hernias noted a 1-year recurrence rate of $27 \%$ with this definition. In the largest review of laparoscopic GPEH repair, Luketich and colleagues ${ }^{3}$ examined their decade of experience and noted a recurrence rate of $15.7 \%$ at a median of 22 months after repair.

Patient satisfaction with their current condition was much improved after GPEH repair. At 1 month, the number of patients that were satisfied with their status jumped from $2.9 \%$ to $85.3 \%$. There was some drop-off over the next 11 months, with $71.4 \%$ of patients satisfied at 1 year. Importantly, small radiographic recurrences had similar satisfaction levels to patients with larger, greater than $2 \mathrm{~cm}$ recurrences $(57 \%$ vs $52.6 \%$ ). This same relationship is seen in the data gathered from the GERD-HRQL questionnaire at 12 months. Patients without recurrence had low total symptom severity scores, whereas those with any recurrence (small radiologic or $>2 \mathrm{~cm}$ ) had a 4-fold increase in the severity of their symptoms.

TABLE 6. Details of symptom recurrence after PEH repair

\begin{tabular}{lcccc}
\hline Symptom time point $(\mathbf{n})$ & Number of patients $(\%)$ & Reflux (6 questions) & Swallowing (2 questions) & Bloating (1 question) \\
\hline Preoperative value & $106(100)$ & $15.0(6.3,21.8)$ & $3.0(0.0,5.0)$ & $3.0(2.0,4.0)$ \\
1 y no recurrence & $68(67.3)$ & $1.0(0.0,7.0)$ & $0.0(0.0,2.0)$ & $1.0(0.0,3.0)$ \\
1 y with recurrence & $33(32.7)$ & $11.0(4.0,17.0)$ & $1.0(0.0,4.0)$ & $2.0(2.0,3.0)$ \\
Small $(\leq 2 \mathrm{~cm})$ & $14(13.9)$ & $10.5(5.5,16.8)$ & $0.0(0.0,2.5)$ & $2.0(1.3,3.0)$ \\
Large $(>2 \mathrm{~cm})$ & $19(18.8)$ & $11.0(3.5,16.5)$ & $2.0(0.0,5.0)$ & $3.0(2.0,3.0)$ \\
$P$ value & & .2624 & .4899 & .2080 \\
\hline
\end{tabular}

Values presented as median (interquartile range) unless stated otherwise. 
These data suggest that any recurrence, no matter the size, negatively impacts patient satisfaction and overall upper gastrointestinal symptoms. The reasoning for the traditional definition of recurrence as greater than $2 \mathrm{~cm}$ is a pragmatic one. In their 2011 randomized trial of biologic mesh reinforcement in laparoscopic GPEH repair, Oelschlager and colleagues ${ }^{19}$ defined recurrence as greater than $2 \mathrm{~cm}$ of stomach above the diaphragm because recurrences could be overestimated due to the variability in radiologist interpretation. In 2013 Lidor and colleagues ${ }^{12}$ determined that a recurrence of over $2 \mathrm{~cm}$ was significant based on symptoms. However, the only symptom that significantly differed between a large recurrence and a smaller less than $2 \mathrm{~cm}$ recurrence was pain with swallowing. Condition satisfaction and overall symptom burden were unchanged when large and small recurrences were compared, a similar finding as in this current prospective study. A change in symptoms after GPEH repair would suggest that a recurrence of the hernia, small or large, may have occurred. Re-evaluation with imaging may be needed at that time if symptoms are causing a detriment to routine function.

\section{Study Limitations}

Although this is a prospective cohort study with complete data, there are some limitations that influence our findings. We were able to capture essentially all consecutive patients who received an elective GPEH repair. However, these results may not apply to urgent or emergent patients who were transferred directly to the hospital without being seen in our outpatient clinic. A second limitation is that although we have excellent 1-year follow-up, 5- and 10year follow-up is required to truly define the natural history of these GPEH repairs and determine factors that can be related to perioperative morbidity and hernia repair durability. Third, because of our sample size of 106 patients, we did not attempt to perform any multivariable regression models to identify predictors of recurrence, patient satisfaction, or symptom severity. A larger, multicenter study would be needed to provide this type of sample size with generalizable results. Our sample size also makes this study underpowered to see any differences between the small recurrence cohort $(\leq 2 \mathrm{~cm})$ and the conventionally defined recurrences $(>2 \mathrm{~cm})$. In addition, because an experience at a single institution is described, the results may not be able to be generalizable to all practices.

\section{CONCLUSIONS}

Using a prospective approach, we examined our experience with GPEH repair with 1-year follow-up. Although the patient population had large, complex PEHs, these were able to be repaired safely with reasonable surgical morbidity. Patient satisfaction and quality of life significantly improved postoperatively. Importantly, when small radiographic recurrences were compared with larger, "conventionally defined" recurrences, there were no differences in 1-year quality of life or patient satisfaction results. Small recurrences were associated with almost-identical symptom severity scores as those seen in larger, more traditionally defined hernia recurrences. These data suggest that all paraesophageal recurrences, no matter the size, may negatively affect symptoms and overall patient satisfaction after GPEH repair. These small recurrences may be important clinically yet have been understudied in the literature.

\section{Webcast}

You can watch a Webcast of this AATS meeting presentation by going to: http://webcast.aats.org/2016/Video/Tuesday/ 05-17-16_Ballroom_IV_1650_Stringham-800.mp4.

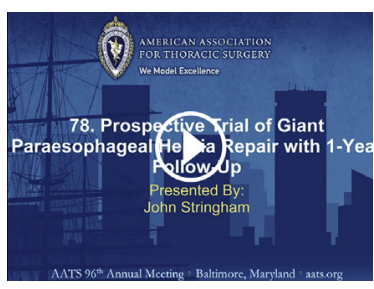

\section{Conflict of Interest Statement}

Authors have nothing to disclose with regard to commercial support.

\section{References}

1. Jobe BA, Aye RW, Deveney CW, Domreis JS, Hill LD. Laparoscopic management of giant type III hiatal hernia and short esophagus. Objective follow-up at three years. J Gastrointest Surg. 2002;6:181-8; discussion 188.

2. Jones R, Simorov A, Lomelin D, Tadaki C, Oleynikov D. Long-term outcomes of radiologic recurrence after paraesophageal hernia repair with mesh. Surg Endosc. 2015;29:425-30.

3. Luketich JD, Nason KS, Christie NA, Pennathur A, Jobe BA, Landreneau RJ, et al. Outcomes after a decade of laparoscopic giant paraesophageal hernia repair. J Thorac Cardiovasc Surg. 2010;139:395-404.e1.

4. Dallemagne B, Kohnen L, Perretta S, Weerts J, Markiewicz S, Jehaes C. Laparoscopic repair of paraesophageal hernia. Long-term follow-up reveals good clinical outcome despite high radiological recurrence rate. Ann Surg. 2011;253: 291-6.

5. Oelschlager BK, Pellegrini CA, Hunter J, Soper N, Brunt M, Sheppard B, et al. Biologic prosthesis reduces recurrence after laparoscopic paraesophageal hernia repair: a multicenter, prospective, randomized trial. Ann Surg. 2006;244:481-90.

6. Nason KS, Luketich JD, Awais O, Abbas G, Pennathur A, Landreneau RJ, et al. Quality of life after collis gastroplasty for short esophagus in patients with paraesophageal hernia. Ann Thorac Surg. 2011;92:1854-60; discussion 60-1.

7. Memon MA, Memon B, Yunus RM, Khan S. Suture cruroplasty versus prosthetic hiatal herniorrhaphy for large hiatal hernia: a meta-analysis and systematic review of randomized controlled trials. Ann Surg. 2016;263:258-66.

8. Luketich JD, Raja S, Fernando HC, Campbell W, Christie NA, Buenaventura PO, et al. Laparoscopic repair of giant paraesophageal hernia: 100 consecutive cases. Ann Surg. 2000;232:608-18.

9. Pierre AF, Luketich JD, Fernando HC, Christie NA, Buenaventura PO, Litle VR, et al. Results of laparoscopic repair of giant paraesophageal hernias: 200 consecutive patients. Ann Thorac Surg. 2002;74:1909-15; discussion 15-6.

10. Nason KS, Luketich JD, Qureshi I, Keeley S, Trainor S, Awais O, et al. Laparoscopic repair of giant paraesophageal hernia results in long-term patient satisfaction and a durable repair. J Gastrointest Surg. 2008;12:2066-75; discussion 75-7. 
11. Patel HJ, Tan BB, Yee J, Orringer MB, Iannettoni MD. A 25-year experience with open primary transthoracic repair of paraesophageal hiatal hernia. J Thorac Cardiovasc Surg. 2004; 127:843-9.

12. Lidor AO, Kawaji Q, Stem M, Fleming RM, Schweitzer MA, Steele KE, et al. Defining recurrence after paraesophageal hernia repair: correlating symptoms and radiographic findings. Surgery. 2013;154:171-8.

13. Lidor AO, Steele KE, Stem M, Fleming RM, Schweitzer MA, Marohn MR. Long-term quality of life and risk factors for recurrence after laparoscopic repair of paraesophageal hernia. JAMA Surg. 2015;150:424-31.

14. Pearson FG, Cooper JD, Ilves R, Todd TR, Jamieson WR. Massive hiatal hernia with incarceration: a report of 53 cases. Ann Thorac Surg. 1983;35:45-51.

15. Whitson BA, Hoang CD, Boettcher AK, Dahlberg PS, Andrade RS, Maddaus MA. Wedge gastroplasty and reinforced crural repair: important components of laparoscopic giant or recurrent hiatal hernia repair. J Thorac Cardiovasc Surg. 2006;132:1196-202.e3.

16. Velanovich V. The development of the GERD-HRQL symptom severity instrument. Dis Esophagus. 2007;20:130-4.

17. Oelschlager BK, Petersen RP, Brunt LM, Soper NJ, Sheppard BC, Mitsumori L, et al. Laparoscopic paraesophageal hernia repair: defining long-term clinical and anatomic outcomes. J Gastrointest Surg. 2012;16:453-9.

18. Hashemi M, Peters JH, DeMeester TR, Huprich JE, Quek M, Hagen JA, et al. Laparoscopic repair of large type III hiatal hernia: objective followup reveals high recurrence rate. J Am Coll Surg. 2000;190:553-60; discussion 60-1.

19. Oelschlager BK, Pellegrini CA, Hunter JG, Brunt ML, Soper NJ, Sheppard BC, et al. Biologic prosthesis to prevent recurrence after laparoscopic paraesophageal hernia repair: long-term follow-up from a multicenter, prospective, randomized trial. J Am Coll Surg. 2011;213:461-8.

Key Words: paraesophageal hernia, long-term outcomes, outcomes research, recurrence, laparoscopy

\section{Discussion}

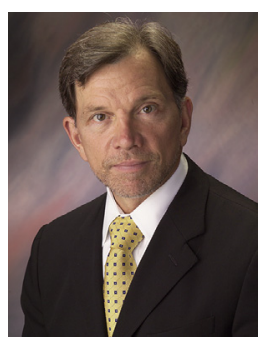

Dr James D. Luketich (Pittsburgh, $P a)$. Dr Stringham, congratulations on a very nice presentation. Thank you for sending me this interesting paper ahead of time to review. I would also like to thank the Association for allowing me to comment on this. I do have a few questions and comments.

Regarding the total reoperative rate, it approaches $8 \%$ by 1 year. I know there were some various reasons for reoperation. I think it is a little high. Did you see this as a function of the learning curve? And of the surgeons listed, how many actually were doing the operation solo, and was there a difference among the surgeons, some early in their learning curve, maybe the more experienced ones starting to get over the learning curve? Did you have enough data to look at that?

Dr John R. Stringham (Charlottesville, Va). During our study period, there were only 5 reoperations for recurrent hernias, 2 which were found immediately after operation and then 3 during the 1-year follow-up period for symptomatic recurrences. We did have 2 immediate reoperations for other reasons: one patient got a J-tube for gastroparesis, for example. Four surgeons performed the PEH repairs, 3 of whom had greater than 5 years' experience before the study began. Two of these surgeons performed $90 \%$ of all the operations. We did not see any difference in recurrence rates or satisfaction between any of our surgeons when we compared, but this study really wasn't powered to look for differences in experience level.

Dr Luketich. Is there a credentialing process by which a new surgeon might start? Can he or she just jump in and do it? How do you work that out, or is that determined?

Dr Stringham. The one surgeon who did not have 5 years' experience was a fellow at our institution and was under the tutelage of the other 3 surgeons during that fellowship. Once he graduated, he began operating independently. Otherwise, there is no credentialing process.

Dr Luketich. I know you reported a $66 \%$ Collis gastroplasty rate. We were doing about that rate in our first couple hundred. As we gain more experience, we are probably down in the low 20th percentile. We see that more as a function of our increased experience gaining length. Did your Collis rate change in the first 25, say, compared with the last 25 ? Were you beginning to see perhaps a little more experience in which you can lower your Collis rate?

Dr Stringham. Unfortunately, we did not really look at a temporal association in any of our variables, and that holds true for Collis gastroplasty rate. We do stress good esophageal mobilization, and if we cannot achieve $3 \mathrm{~cm}$ of esophagus in the abdomen with absolutely no tension, we will perform a Collis gastroplasty. I don't believe our rate of gastroplasty has decreased over time but, unfortunately, we did not really look for temporal differences over our brief study time period of 3 years.

Dr Luketich. I think it is an important part of the operation in a lot of patients. I don't know the exact number, but there are a lot of groups out there that would report a much lower rate. That is why I ask.

I think one of the most interesting points of the paper is that, regardless of the size, you really tried to sort that out very nicely, but I don't think all papers have done that. Can you explain why that patient with a $1-\mathrm{cm}$ recurrence might be just as likely to have symptoms as that $4-\mathrm{cm}$ recurrence? In other words, do you think it's vagal injury; is it too tight a wrap? In your reoperations and in your symptoms, even though some didn't need a reoperation yet, I would predict some will if you have, again, a lowering of the patient satisfaction level. Do you see other causes besides herniation that might cause this symptom recurrence?

Dr Stringham. Well, when we looked at the gastroesophageal reflux disease (GERD) scoring system, it was mostly GERD symptoms that were present in both groups. There really wasn't any difference in dysphagia, shortness of breath, anything else.

Dr Luketich. So if it is not a herniation, what is it?

Dr Stringham. That is a good question. I still think these patients, even with a small, hiatal hernia, essentially a type I hiatal hernia, still have some amount of GERD-type symptoms in which you don't have the usual orientation of the gastroesophageal junction in the abdomen, thus allowing 
for the same symptoms of GERD that one sees in the larger recurrences.

Dr Luketich. The last question is, as you know, most of the other reports out there have talked about the small, relatively asymptomatic ones, and we noticed that, too, in that patients who had the small, less than $2-\mathrm{cm}$ recurrence, our reoperation rate is as low as $3 \%$. If you get up above, say, a $30 \%, 40 \%$ recurrence, you are getting up to an extremely high rate. Did you see any correlation at all with size, and are you concerned that the symptom rate may get worse over time?

Dr Stringham. I definitely am concerned that the symptoms will get worse over time. While we did not look at the very long term -5 or 10 years out - there have been some studies out there that did look at much longer timeframes, 8 years, 10 years median time from the operation to their re-evaluation with a swallow study. There is one study I can remember that actually has a $66 \%$ recurrence rate with a median follow-up time of 99 months. The worry is that these small recurrences will get larger over time, and that is why we are seeing much larger recurrences in the distant future in these other studies with longer follow-up.

Dr Luketich. I applaud your follow-up. That is great, great data, and I think that is the way to follow these patients, very closely.

Dr Stringham. Thank you.

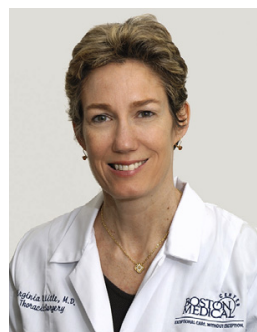

Dr Virginia R. Litle (Boston, Mass). I have some questions about BMI. You had a range of 30 to 40 ?

Dr Stringham. Yes.

Dr Litle. How many or what percentage of your patients had a BMI preoperatively greater than 35 ? That is really morbidly obese.

Dr Stringham. We had 15 patients with a BMI greater than 35 . We had 4 recurrences in that group. Two were very small, and then 2 were of the more conventional definition.

Dr Litle. Yes, that was one of my questions, the BMI in the recurrent group. It was very small. What percentage was that?

Dr Stringham. I believe that is about a $12 \%$ recurrence rate in those that had a BMI over 35 .

Dr Litle. Do you ever give consideration to performing some sort of weight-loss surgery in conjunction with the repair of the PEH in the morbidity obese, since it is known to be associated with recurrence?

Dr Stringham. We definitely do. We do not often choose to perform this operation in the morbidly obese: those 15 patients that were done with a BMI greater than 35 , these patients had extenuating circumstances that required us to help fix them.

Dr Litle. Like with a sleeve or something?
Dr Stringham. We routinely these days do counsel our patients about weight-loss surgery, and we will send our patients to at least discuss that with one of our bariatric surgeons.

Dr Litle. Before you do the elective paraesophageal?

Dr Stringham. Nowadays we do. When this dataset was done, we would occasionally do these operations on patients with larger BMIs.

Dr Litle. Thanks.

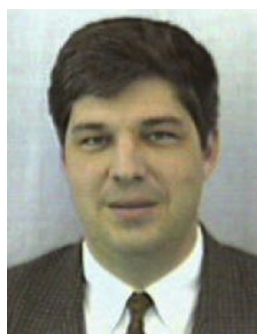

Dr Stephen R. Hazelrigg (Springfield, Ill). There are a lot of variables in how people do these operations. Some use patches, some do all sorts of things, but one thing that we have started to do that I do think has helped is using the hernia sac itself and pexying it to the anterior abdominal wall. Did you do any sort of gastropexy routinely with these?

Dr Stringham. We do a routine gastropexy of the wrap to the crura, to the outside of the crura, to ensure that it stays in place. For large hernias, occasionally we will do another pexy to the anterior abdominal wall, but we don't use the hernia sac.

Dr Hazelrigg. We started doing that several years ago, again, on a lark, and I think it really holds the gastroesophageal junction down, and in these big hernia sacs, it is easy to do. You might want to consider it. We have been looking at it and it has decreased our recurrent herniation rate.

The second and last question, the true PEH you have included in these, did they behave any differently or were the outcomes and results the same as the other giant hernias?

Dr Stringham. True paraesophageals being type IIs. The group we have is very small, and so, unfortunately, I don't think we can really comment too much on any differences in their natural history.

Dr Hazelrigg. Thank you.

Dr Andrew W. Chang (Ann Arbor, Mich). I enjoyed your talk.

I have a couple questions regarding the Collis gastroplasty. Did your technique to perform the gastroplasty differ between the laparoscopic and transthoracic operations?

Dr Stringham. Yes. We perform a wedge fundectomy for the laparoscopic procedures and then a Belsey-Collis for the thoracotomy.

Dr Chang. While I understand that the sample size is small for any kind of multivariable analysis, for the patients who had "lengthening" versus those who had not, did you see any trends in terms of the recurrence rates? Did it make a difference or was there an equal distribution for recurrent hernias?

Dr Stringham. We did not look at that, but I think that will be something we will do in the future for sure. 


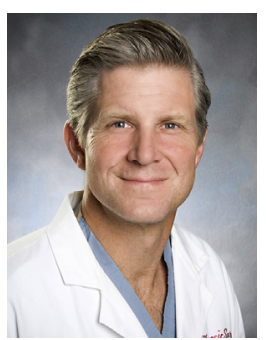

Dr Scott J. Swanson (Boston, Mass). I enjoyed your paper.

I may have missed this. Did you mention how many patients had delayed emptying? Did you look for that as a postoperative problem?

Dr Stringham. We do routinely look at delayed gastric emptying clinically, and occasionally we had to intervene with those patients that do experience this. I am not sure it was one of the variables that we prospectively identified in our database. Therefore, I am not sure of the answer to your question.

Dr Swanson. Do you look for the vagal nerves or do you just stay away from them? Do you have a specific protocol on that?

Dr Stringham. Routinely we try to preserve the vagal nerves and ensure their integrity.

Dr Swanson. So you look and identify them and then put them inside your wrap procedure or outside?

Dr Stringham. We routinely will put them inside the wrap. Again, the operations from this study were performed a couple of years ago, and there could have been a practice change I am unaware of, but in my experience at our institution, that is what we do.

Dr Swanson. My last question, do you have a theory as to why there is such a high recurrence rate of any kind? Is it that we are not taking enough of the sac out; we don't close the hiatus tight enough; we don't mobilize enough? What is your theory about 33\%, $40 \%$ recurrences that get even bigger over time? What is it that we are not doing adequately?

Dr Stringham. I think that we have been trying to determine that for years now, why we are having such high recurrence rates, what we are doing wrong. Is it because we are not doing an adequate job of esophageal lengthening, ensuring adequate intra-abdominal esophagus, do our wraps need to be done differently, do we need routine gastropexy? I think we are unfortunately doing all these things, and there is so much variability in technique because no one really knows how to improve the recurrence rates.

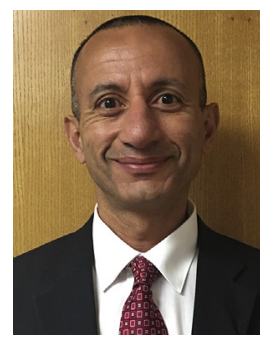

Dr Abbas E. Abbas (Philadelphia, $P a$ ). You showed a dissociation between the symptoms and the size of the recurrence. How would you recommend we follow these patients and for how long? Should it be based on symptoms or should we bring them back and rescan them at certain intervals?

Dr Stringham. I think we definitely have to look at their symptoms because that is what is going to drive any other interventions that occur. My recommendation would be to continue to watch their symptoms, and if they come to a point at which it interferes with their life, then most likely they need to be reimaged, and possibly reintervened, if appropriate.

Readers who found these articles interesting may also like to read the following papers found in recent and future issues of our sister publications, Seminars in Thoracic and Cardiovascular Surgery and Operative Techniques in Thoracic and Cardiovascular Surgery!

Thoracic: Esophagus

ORIGINAL SUBMISSION: Black and White Esophagus: Rare Presentations of Severe Esophageal Ischemia. Daniel B. Kim. Semin Thoracic Surg 2017: In press.

Editorial Commentary: Black Esophagus, White Esophagus, or Shades of Gray? Justin D. Blasberg. Semin Thoracic Surg 2017: In press.

STATE OF THE ART: The State of The Art in Per-Oral Endoscopic Myotomy. Stavros N. Stavropoulos. Semin Thoracic Surg 2016: $137-146$. 